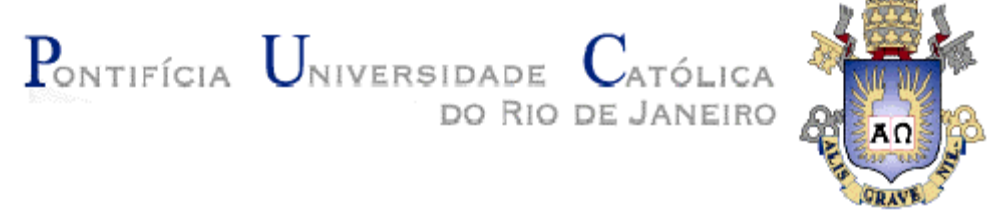

Elisa Maria Pinheiro de Souza

\title{
Letramento digital: um estudo sobre a formação de discentes do Curso de Letras da UEPA
}

\section{Tese de Doutorado}

Tese apresentada ao Programa de PósGraduação em Educação do Departamento de Educação da PUC-Rio como parte dos requisitos parciais para obtenção do título de Doutor em Educação.

Orientador: Prof ${ }^{a}$ Maria Apparecida C. Mamede Neves

Co-orientador: Profa Maria do Perpétuo Socorro C. da Silva 


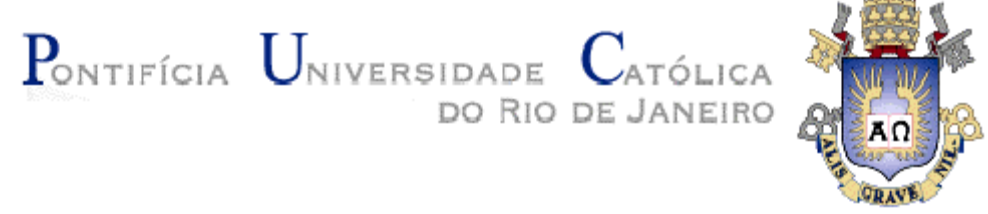

Elisa Maria Pinheiro de Souza

\section{Letramento digital: um estudo sobre a formação de discentes do Curso de Letras da UEPA}

Tese apresentada como requisito parcial para obtenção do título de Doutor pelo Programa de Pós-Graduação em Educação do Departamento de Educação do Centro de Teologia e Ciências Humanas da PUC-Rio. Aprovada pela Comissão Examinadora abaixo assinada.

Profa Maria Apparecida C. Mamede Neves

Orientadora

Departamento de Educação - PUC-Rio

Prof ${ }^{a}$ Maria do Perpétuo Socorro C. da Silva Departamento de Língua e Literatura - UEPA

Profa . Rosália Maria Duarte Departamento de Educação - PUC-Rio Profa. Stella Maria de Azevedo Pedrosa CCEAD - PUC-Rio Profa. Stella Cecília Segenreich UCP

Prof ${ }^{a}$ Flávia Nízia da Fonseca Ribeiro INFNET

Prof. Paulo Fernando C. de Andrade Coordenador Setorial do Centro de Teologia e Ciências Humanas

Rio de Janeiro, 10 de setembro de 2010. 
Todos os direitos reservados. É proibida a reprodução total ou parcial do trabalho sem autorização da universidade, da autora e do orientador.

\section{Elisa Maria Pinheiro de Souza}

Graduou-se em Letras na UFPA (Universidade Federal do Pará) em 1977. Concluiu o curso de Mestrado em Educação - Docência Universitária no IPLAC (Instituto Pedagógico Latinoamericano Y Caribeño). Desempenhou as funções de chefia do Departamento de Língua e Literatura e de coordenador do Curso de Letras do CCSE/UEPA (Centro de Ciências Sociais e Educação/Universidade do Estado do Pará. Participou de diversos eventos na área educacional. É responsável pelo desenvolvimento das atividades do Curso de Letras na modalidade a distância.

Ficha Catalográfica

Souza, Elisa Maria Pinheiro de

Letramento digital : um estudo sobre a formação de discentes do curso de letras da UEPA / Elisa Maria Pinheiro de Souza ; orientadora: Maria Apparecida C. Mamede

172 f. ; il. ; $30 \mathrm{~cm}$ Neves. -2010

Tese (doutorado)- Pontifícia Universidade Católica do Rio de Janeiro, Departamento de Educação, 2010. Inclui bibliografia

1. Educação - Teses. 2. Tecnologias digitais. 3. Formação de professores. 4. Curso de letras. I. Neves, Maria Apparecida C. Mamede Neves. II. Pontifícia Universidade Católica do Rio de Janeiro. Departamento de Educação. III. Título. 


\section{Agradecimentos}

À memória de meus pais,

Hamilton Maia Pinheiro e Maria Lúcia Santos Pinheiro

A DEUS, único e soberano, por ter estado presente nos bons momentos e nas horas difíceis desta jornada.

Aos meus filhos Sheila, João Hamilton e Elinelson, às minhas noras Kelly e Dione e aos meus netos Yuri, Elian, Camila e Yana, por terem sido, na verdade, o grande estímulo para a concretização desta caminhada.

Ao meu esposo Manoel, pelo incentivo, compreensão e carinho dispensados ao longo desta jornada.

À minha irmã Milizaura e aos meus sobrinhos Luis Fernando e Paula pelo incentivo nos momentos de inquietação.

À minha orientadora Prof ${ }^{a}$. Dr. Maria Apparecida C. Mamede Neves, que gentilmente me acolheu como sua orientanda na PUC-Rio, em especial pela orientação serena, sensível e segura; e à Prof ${ }^{a}$. Dr. Maria do Perpétuo Socorro Cardoso da Silva, pelo acompanhamento, leituras e sugestões na qualidade de coorientadora. Ambas me ajudaram a trilhar o árduo caminho da pesquisa.

À Universidade do Estado do Pará (UEPA), na pessoa do Prof. Dr. Sílvio Gusmão, Pró-Reitor de Pesquisa e Pós-Graduação, pelo empenho que viabilizou a parceria com a Pontifícia Universidade Católica do Rio de Janeiro (PUC-Rio), e, a esta, na pessoa da Prof ${ }^{a}$. Dr. Maria Inês Marcondes, Coordenadora do Programa de Pós-Graduação em Educação, por nos oferecer todo apoio, suporte acadêmico e grandes mestres. 
Ao Prof. Dr. Emmanuel Cunha, responsável pelo elo desta parceria e representante da UEPA, pelo empenho em resolver os trâmites burocráticos e acadêmicos, frente às nossas inquietações.

À Direção do Centro de Ciências Sociais e Educação da UEPA, na pessoa da Prof $^{a}$. Ms. Ana Cláudia S. Hage, que, no exercício da direção deste Centro, quando iniciou esta parceria, não mediu esforços para que, enfim, iniciássemos este Doutorado, e à Prof ${ }^{a}$. Ms. Maria José de Souza Cravo, atual diretora do Centro, por garantir, mesmo com todas as adversidades burocráticas inerentes às IES públicas, que chegássemos aqui, e em especial pela sua amizade.

Às professoras Dr. Rosália Duarte, Dr Stella Cecília Segenreich, Dr. Stella Maria Pedrosa, Dr. Flávia Ribeiro, Dr. Marcella Fernandez e Dr. Gilda Bernardino pela leitura, apontamento e sugestões feitas como membros da Banca de Qualificação I e II; e por aceitarem o convite para compor a BANCA DE DEFESA e, assim, compartilharem comigo seus conhecimentos, mais uma vez, o que muito me honrou.

Aos alunos do Curso de Letras de Belém, Moju, Paragominas e Vigia, que se dispuseram a participar deste estudo.

Aos meus colegas de turma, e em especial a Maria de Lourdes Melo, Irene Rodrigues, José Roberto Alves e Marco Antonio Camelo, pelo aprendizado da convivência e aceitação um do outro.

Aos amigos e familiares que, de uma forma ou outra, contribuíram para a realização deste trabalho.

A todos, meu muito obrigada! 


\section{Resumo}

Souza, Elisa Maria Pinheiro de; Mamede Neves, Maria Apparecida C. Letramento digital: um estudo sobre a formação dos discentes do Curso de Letras da UEPA. Rio de Janeiro, 2010. 172p. Tese de Doutorado Departamento de Educação, Pontifícia Universidade Católica do Rio de Janeiro.

O avanço das tecnologias da informação e da comunicação e o processo de globalização suscitam uma reorganização nos espaços acadêmicos para atender às demandas de uma clientela que vivencia as possibilidades da cultura digital. Com esse pano de fundo e refletindo sobre a inserção do discente em um novo contexto de ensino, esta investigação objetivou a análise da relação entre letramento digital e a formação de discentes. Foi um estudo de abordagem exploratória, de cunho quantiqualitativo, realizado no período de 2008 a 2009, no âmbito do Curso de Letras da Universidade do Estado do Pará, no campus de Belém, Moju, Paragominas e Vigia. A produção dos dados incluiu a análise dos Projetos Políticos Pedagógicos das licenciaturas da instituição e os dizeres dos discentes por meio da aplicação de questionário, e teve como aporte teórico, as idéias de Pretto (2004), Tardif (2007, 2008), Moscovici (2007) e Jodelet (2001), entre outros. Participaram desse estudo 150 alunos do Curso de Letras, sendo 74 integrantes de turmas do $1^{\circ}$ ano (ano letivo de 2008) e 76 prováveis concluintes de 2009. Os resultados permitiram caracterizar o perfil dos discentes e sua familiaridade com as tecnologias digitais, identificar as representações que constroem sobre algumas mídias e a visão que revelam sobre a relação entre o uso dessas tecnologias e a formação que recebem nesta IES. Eles também indicaram que embora a IES registre, nos documentos oficiais, a necessidade do domínio de tecnologias pelos alunos, ele não é priorizado no Curso sob análise, tanto que o panorama não é propício à disseminação do uso do computador como ferramenta para a aprendizagem de processos tecnológicos, pois é percebido apenas como instrumento facilitador das tarefas do cotidiano acadêmico. A pesquisa apontou a necessidade de ampla reflexão sobre concepções que embasam não só a construção do desenho curricular desta licenciatura, bem como princípios que norteiam práticas pedagógicas nesse processo de formação.

\section{Palavras-chave:}

Tecnologias digitais; formação de professores; curso de Letras; letramento digital; representações midiáticas. 


\section{Abstract}

Souza, Elisa Maria Pinheiro de; Mamede Neves, Maria Apparecida C. (Advisor) Digital literacy: a study on the formation of students of the Letters course of UEPA. Rio de Janeiro, 2010. 172p. Thesis Departamento de Educação, Pontifícia Universidade Católica do Rio de Janeiro.

The advance of the information and communication technologies and the process of globalization provokes a reorganization in the academic spaces in order to deal with the demands of a group who experience the possibilities of digital culture. Concerning this background and reflecting about the insertion of the student in a new context of teaching, this investigation aimed to analyze the relation between digital literacy and students' formation. It was a study of an exploratory approach, of a quantitative and qualitative type, carried out in the period of 2008 and 2009, related to the Letters Course of the Universidade do Estado do Para (UEPA), in the campi of Belem, Moju, Paragominas and Vigia. The data production included the analysis of the Pedagogical Projects of the undergraduate courses of the institution as well as the speeches of the students that answered a questionnaire, and it had as theoretical base the ideas of Pretto (2004), Tardif (2007, 2008), Moscovici (2007) and Jodelet (2001), among other authors. 150 students of the Letters Course took part of this study, 74 of them were in the first grade classes (school year of 2008) and 76 students were probably going to graduate in 2009. The results allowed to characterize the students' profile and their familiarity with digital technologies, to identify the ideas they construct about some media and the opinion they reveal about the relation between the usage of these technologies and the formation they receive in this university. The students also indicated that although this institution records in its official documents the necessity of students being competent concerning the usage of these technologies, this is not a priority in the analyzed course, once they are only perceived as an instrument that facilitates the tasks of academic daily. The research pointed to the necessity of a wide reflection on conceptions that are the base of both the construction of this undergraduate course and the principles that guide the pedagogical practices in this formation process.

\section{Key-words:}

Digital technologies; teachers' formation; Letters course; digital literacy; media representation. 


\section{Sumário}

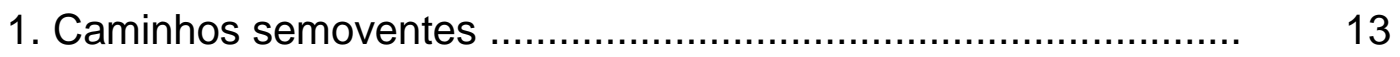

2. Um fio nas tramas das redes ................................................

2.1. Tipo de Estudo ................................................................... 31

2.2. Tão perto, e tão longe ……………...................................

2.3. Perfil dos entrevistados .........................................................

2.4. Ferramentas de navegação ................................................ 46

2.5. Caminhos investigativos ................................................... 47

3. Um olhar sobre os cursos de licenciaturas no Pará ..................... $\quad 55$

3.1. O Estado do Pará ……………..........................................

3.2. O cenário paraense do ensino superior .................................... 64

3.3. UEPA: a instituição de ensino superior do estado do Pará ...... 78

3.4. O Curso de Letras da UEPA ............................................... $\quad 79$

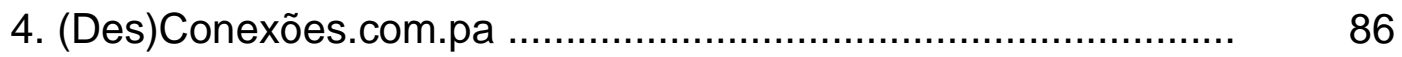

4.1. Os Projetos Políticos Pedagógicos dos Cursos de Licenciatura da UEPA ........................................................ 88

4.1.1. A análise dos Projetos Políticos Pedagógicos ..................... $\quad 90$

4.2. As tecnologias digitais na formação dos discentes do Curso de Letras da UEPA .................................................................. 98

4.2.1. Os discentes e a tecnologia .............................................. 102

4.2.2. O letramento digital dos alunos .......................................... 134

4.2.3. As representações sobre as mídias pelos discentes de Letras ...................................................................... 138

4.2.4. Desconexas conexões ........................................................ 149

5. Com um click ..................................................................... 163

6. Referências Bibliográficas ………………………………..... 169

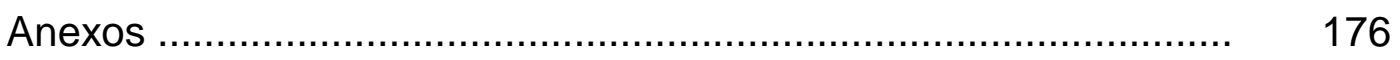

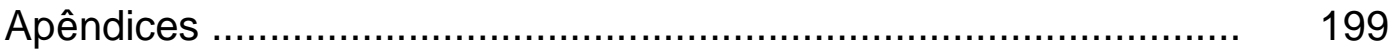




\section{Lista de Figuras}

Figura 1 Lócus da pesquisa ..............................................

Figura 2 Centro de Ciências Sociais e Educação - Belém ...... 36

Figura $3 \quad$ Núcleo de Paragominas .......................................... 38

Figura $4 \quad$ Núcleo de Moju .................................................. 41

Figura $5 \quad$ Núcleo de Vigia de Nazaré ...................................... 43

Figura 6 Localização do Estado do Pará no mapa do Brasil ... 56

Figura $7 \quad$ Mesorregiões do Pará ............................................ 58

Figura $8 \quad$ A economia paraense: da floresta à cidade .............. $\quad 65$

Figura 9 Localização dos campi das IES/Município ................ $\quad 73$

Figura 10 Leitores $X$ situação econômica .................................. 160

Figura $11 \quad$ O tipo de suporte …….......................................... 161

Figura 12 Lugares onde os leitores costumam ler livro ............. 161 


\section{Lista de Quadros}

Quadro 1 Alunos ingressantes ............................................. 46

Quadro 2 Prováveis concluintes ............................................... 46

Quadro $3 \quad$ Mesorregiões e respectivos municípios .................... 59

Quadro $4 \quad$ IDH estados brasileiros ........................................... 162 


\section{Lista de tabelas}

Tabela $1 \quad$ Síntese dos dados de Belém ........................................ 35

Tabela 2 Síntese dos dados de Paragominas ............................. 37

Tabela 3 Síntese dos dados de Moju ........................................ 40

Tabela $4 \quad$ Síntese dos dados de Vigia de Nazaré .......................... 42

Tabela 5 Síntese dos dados geo-sócio-econômicos do Pará ........ 57

Tabela 6 Número de pessoas com renda domiciliar per capita inferior à linha da pobreza .......................................... 62

Tabela 7 Síntese de indicadores sociais 2009 - uma análise das condições de vida da população brasileira ................... 63

$\begin{array}{lll}\text { Tabela } 8 \text { Instituições segundo a categoria administrativa - Pará .. } & 70\end{array}$

Tabela9 Quantitativo de instituições segundo a organização acadêmica - Pará .................................................... 74

Tabela 10 Cursos/Turmas - Consórcio interinstitucional SEDUC/UEPA ....................................................... 76

Tabela 11 Percentual de pessoas com acesso à internet e posse de telefone móvel celular para uso pessoal no Pará ..... 99

Tabela 12 Idade e sexo dos entrevistados ..................................... 103

Tabela 13 Meios de comunicação usados no tempo livre dos entrevistados ......................................................... 104

Tabela 14 Fontes informativas usadas pelos entrevistados .......... 106

Tabela 15 Opções de estudo de um mesmo assunto ..................... 107

Tabela 16 Uso do computador ................................................... 108

Tabela 17 Tempo de uso do computador .................................... 109

Tabela 18 Forma de aquisição de conhecimento para o manuseio do computador ...................................................... 110

Tabela 19 Uso do computador para trabalhar/estudar .................... 111

Tabela 20 Uso do computador no tempo livre .............................. 111

Tabela 21 Postura diante do computador ..................................... 112

Tabela 22 Mudanças de postura com o uso do computador .......... 113

Tabela 23 Computador em casa ................................................ 113

Tabela 24 Razões para a compra de computador .......................... 114 
Tabela 25 Quantitativo de computadores .................................... 115

Tabela 26 Localização do computador ......................................... 115

Tabela 27 Compartilhamento do computador ............................... 116

Tabela 28 Parceiros no compartilhamento do computador ............. 116

Tabela 29 Mudanças com o uso do computador ............................ 118

Tabela 30 Navegação na internet ............................................. 119

Tabela 31 Freqüência de acesso à internet .................................. 119

Tabela 32 Local de acesso à internet ......................................... 120

Tabela 33 Finalidade de uso da internet ....................................... 121

Tabela 34 Uso dos serviços disponíveis na internet ...................... 122

Tabela 35 Aspectos significativos para a compreensão dos conteúdos dos sites .................................................... 123

Tabela 36 Ações realizadas no momento de conexão com a internet ............................................................ 125

Tabela 37 Bloqueio de mensagens publicitárias ........................... 126

Tabela 38 Mudanças ocorridas com a instalação de internet em casa

Tabela 39 Lembranças do tempo em que não havia internet em casa

Tabela 40 Visitas ao site da UEPA

Tabela 41 Uso da internet na UEPA

Tabela 42 Existência de regulamento da UEPA para uso da internet

Tabela 43 Uso da internet na UEPA

Tabela 44 Grau de interesse de questões vinculadas à internet .... 132

Tabela 45 Uso da internet no Ensino Médio ................................ 133

Tabela 46 Recursos da internet ................................................. 133

Tabela 47 Vivência de coisas impossíveis .................................... 134

Tabela 48 Quantitativo dos registros categorizados - livro ............. 141

Tabela 49 Quantitativo dos registros categorizados - televisão ...... 144

Tabela 50 Quantitativo dos registros categorizados computador...................................................... 145

Tabela 51 Quantitativo dos registros categorizados - internet ....... 146 